\title{
The efficacy and safety of antiepileptics in the prophylaxis of pediatric migraine: the meta-analysis of randomized controlled trials
}

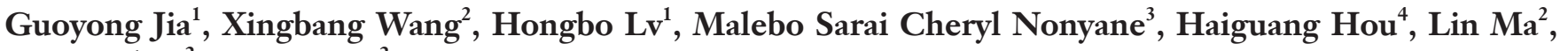 \\ Peiyan $\operatorname{Shan}^{2}$, Xinwei $\mathrm{Wu}^{2}$ \\ ${ }^{1}$ Department of Neurology, Qilu Hospital, Cheeloo College of Medicine, Shandong University, Jinan, China; ${ }^{2}$ Department of Geriatrics, Qilu \\ Hospital, Cheeloo College of Medicine, Shandong University, Jinan, China; ${ }^{3}$ Qilu Medical College of Shandong University, Jinan, China; ${ }^{4}$ Tianjin \\ Centers for Disease Control and Prevention, Tianjin, China \\ Contributions: (I) Conception and design: All authors; (II) Administrative support: G Jia, X Wang, L Ma, P Shan, X Wu; (III) Provision of study \\ materials or patients: G Jia, X Wang, H Hou, L Ma, X Wu; (IV) Collection and assembly of data: G Jia, X Wang, H Hou, P Shan, X Wu; \\ (V) Data analysis and interpretation: G Jia, X Wang, H Lv, H Hou, L Ma, P Shan, X Wu; (VI) Manuscript writing: All authors; (VII) Final approval \\ of manuscript: All authors. \\ Correspondence to: Xinwei Wu. Department of Geriatrics, Qilu Hospital, Cheeloo College of Medicine, Shandong University, Jinan 250012, China. \\ Email: 15874292620@163.com.
}

Background: Migraine is the most common primary headache among children and adolescents. The aim of this meta-analysis was to evaluate the efficacy and safety of antiepileptic drugs in the prevention of pediatric migraine.

Methods: PubMed, Cochrane Library, EMBASE and Chinese National Knowledge Infrastructure (CNKI) databases were searched for eligible published RCTs from January 1970 to June 2020. Migraine frequency and $\geq 50 \%$ response rate were measured as the efficacy outcomes. We used "Risk of Bias" tool for quality assessment and RevMan5.3 software for statistical analysis.

Results: Four articles containing 7 RCTs with 794 participants compared the efficacy of AEDs with placebo. Four RCTs assessed topiramate vs. placebo and 3 RCTs evaluated divalproex sodium extendedrelease (DVPX ER) vs. placebo. The results demonstrated that children receiving antiepileptic drugs had a significant advantage in remitting the mean monthly migraine days compared to those who received placebo, with an MD of -0.48 ( $\mathrm{n}=930,95 \% \mathrm{CI}:-0.84$ to $-0.12, \mathrm{Z}=2.60, \mathrm{P}=0.009)$. Topiramate significantly reduced monthly migraine days ( $\mathrm{MD}=-0.70, \mathrm{n}=489,95 \% \mathrm{CI}:-1.16$ to $-0.25, \mathrm{Z}=3.01, \mathrm{P}=0.003$ ) but failed to improve the $\geq 50 \%$ response rate $(M D=-1.50, n=489,95 \% \mathrm{CI}: 0.70$ to $3.22, \mathrm{Z}=1.05, \mathrm{P}=0.30)$. DVPX ER did not significantly reduce monthly headache frequency ( $\mathrm{n}=441,95 \% \mathrm{CI}:-0.70$ to $0.47, \mathrm{Z}=0.38, \mathrm{P}=0.70$ ) or improve the $\geq 50 \%$ response rate $(n=441,95 \% \mathrm{CI}: 0.59$ to $1.25, \mathrm{Z}=0.82, \mathrm{P}=0.41)$ compared with placebo. Topiramate and DVPX ER were related to higher rates of side effects and adverse reactions.

Discussion: Topiramate can reduce monthly headache days in children and adolescents with migraine. However, it failed to improve the $\geq 50 \%$ response rate. DVPX ER showed no difference from placebo in the prophylactic treatment pediatric migraine. Side effects seemed to be more frequent in topiramate and DVPX ER treated children but generally well-tolerated.

Keywords: Antiepileptics; pediatric; migraine; prevention; meta-analysis

Submitted Dec 28, 2020. Accepted for publication Jun 10, 2021.

doi: $10.21037 / \mathrm{tp}-20-478$

View this article at: https://dx.doi.org/10.21037/tp-20-478 


\section{Introduction}

Migraine is the most common primary headache among the pediatric population (1), with the prevalence that increased from $3-5 \%$ of children to $10-20 \%$ among adolescents (2-4). Clinical symptoms of pediatric migraine are often atypical. Children and adolescents patients with migraine may present with episodic vertigo, dizzy, nausea, vomiting, and others. Headache is a disabling health condition among children and adolescents. Studies have proved that most migraine occurs between $6 \mathrm{AM}$ to $6 \mathrm{PM}$ in children (5), affecting their school attendance, academic performance, and social interactions with their peers and families $(6,7)$.

Experts have advised that if patients have more than 2 migraine episodes per week or the attacks interfere with their quality of life and cause significant disability, then prophylactic migraine treatment must be initiated (8). The prophylactic treatment for pediatric migraine consists of non-pharmaceutical and pharmaceutical treatment (9). Drug interventions mainly includes acute and prophylactic medications. Acute drugs aim to relieve or stop the acute headache and the accompanying symptoms. Prophylactic treatment intends to reduce the frequency, duration, and severity of headache $(10,11)$.

At present, preventive drugs for pediatric migraine include calcium channel blockers, tricyclic antidepressants, $\beta$-adrenergic blockers, antiepileptic drugs (AEDs) and Botulinum toxin A. In 2019, the American Academy of Neurology and the American Headache Society published practice guidelines on all the preventive medications for pediatric migraine (12) which demonstrated that the evidence for divalproex, onabotulinumtoxin-A, amitriptyline, nimodipine, and flunarizine to reduce headache frequency in children and adolescents was insufficient. Topiramate, propranolol and cinnarizine seemed to be more likely effective for pediatric migraine prevention. However, we noticed the guidelines had some limitations. Both migraine and epilepsy are episodic neurological disorders (13) and the pathogenesis of the two diseases was postulated to be related to neuronal hyperexcitability (14). AEDs such as valproate, topiramate, and levetiracetam have been proved to be effective for the prevention of episodic migraine in adults $(15,16)$. However, there are very few studies on the efficacy and safety of antiepileptics in pediatric migraine prophylaxis and the limited trials have yielded disproportionate results. We conducted this meta-analysis of randomized controlled trials (RCTs) to investigate the efficacy and safety of antiepileptics in the prophylaxis of episodic migraine in children and adolescents.

\section{Methods}

\section{Search strategy}

Cochrane Library, PubMed and EMBASE databases were searched to identify all eligible RCTs published from January 1970 (17) to December 2019 with no language restrictions. The search strategies included the following key words such as "pediatric migraine/headache/headache pain" or "child/children/childhood migraine/headache/ headache pain" or "adolescent/adolescents migraine/ headache/headache pain" or "migraine/headache/ headache pain in child/children" or "migraine/headache/ headache pain in adolescents" AND "antiepileptic drugs" or "antiepileptics" or "valproate" or "valproate acid" or "sodium valproate" or "divalproex sodium" or "magnesium valproate" or "topiramate" or "topamax" or "gabapentin" or "pregabalin" or "lamotrigine". Case reports, reviews, reference lists of related publications and conference abstracts were also scanned to identify relevant studies.

\section{Selection criteria}

This study was performed according to the Preferred Reporting Items for Systematic Reviews and MetaAnalyses (PRISMA) guidelines (available at https://dx.doi. org/10.21037/tp-20-478) (18). The inclusion criteria were as follows: (I) double-blind randomized controlled trials (RCTs) taking antiepileptics in migraine prophylaxis; (II) participants were $\leq 18$ years old and they were diagnosed with episodic migraine according to the International Classification of Headache Disorders II (ICHD-II) or the International Classification of Headache Disorders, third edition (ICHD-3, beta version); (III) available and complete efficacy outcomes were reported. The exclusion criteria were: (I) trials other than RCTs such as cross-over designs, open-labeled studies, healthy controlled trials, and others; (II) animal trials; (III) studies evaluating the efficacy of two drugs but no placebo.

\section{Quality assessment}

The quality of the included trials was assessed independently by two experienced authors (Jia G and X Wang) using to the "Risk of Bias" tool in Review Manager Software version 
5.3. Discrepancies were resolved by consultation with the corresponding author $(\mathrm{X} \mathrm{Wu})$. Seven items containing random sequence generation, allocation concealment, blinding of participants and personnel, blinding of outcome assessment, incomplete outcome data, selective reporting and other bias were evaluated.

\section{Data extraction}

Two experienced authors independently searched the title and abstract of each study to identify all eligible trials. Disagreements between the two authors were settled by discussion or consultation with the corresponding author $(\mathrm{X} \mathrm{Wu})$. Important information including patients' characteristics, the kind, dose and duration of antiepileptic drugs and outcomes were abstracted from the suitable trials. According to the International Headache Society (IHS) recommendations (19), we regarded mean monthly headache days post-treatment and proportion of children who experienced a $\geq 50 \%$ reduction in monthly migraine days as the efficacy outcomes in this study. Besides, percentages of participants discontinuing for any reason and participants dropout because of adverse effects in the study were extracted for the feasibility analysis.

\section{Statistical analysis}

RevMan5.3 software (Cochrane Information Management System) was used for all of the statistical analyses. Dichotomous outcomes were analyzed with risk ratios (RRs) and 95\% confidence intervals (CIs). Continuous variables were calculated with differences (MDs) and 95\% CIs. The significant level was 0.10 for heterogeneity tests and 0.05 for others. $\mathrm{I}^{2}$ was used to evaluate heterogeneity. $\mathrm{I}^{2} \leq 50 \%$ indicated the heterogeneity was acceptable, then we analyzed the data with the fixed-effects model. If $\mathrm{I}^{2}$ was $>50 \%$, the random-effects model was used.

\section{Results}

\section{Search findings}

Overall, 833 potential studies were initially identified for this analysis after searching the aforementioned databases. After searching the titles and abstracts, 60 potentially eligible full-text articles were retrieved (Figure 1). We ultimately screened the exclusion and inclusion criteria and identified 4 studies including 7 trials in this analysis (Table 1).

\section{Characteristics of included studies}

Four studies (20-23) comprised of 7 RCTs with 794 participants compared the efficacy of AEDs with placebo. Ethnic groups included Caucasian, Asian, African, and others. Three articles assessed topiramate. One of these papers included two dose treatments of topiramate (50 and $100 \mathrm{mg} / \mathrm{d}$ ), so we considered it as two separate trials. One study (20) had three groups: topiramate, amitriptyline, and placebo. The amitriptyline group's data was not included in this analysis. The dose of topiramate was increased gradually in the trials and the treatment duration lasted 16-31 weeks. Another trial (23) recruited 305 patients to evaluate the efficacy of 3 different doses (250,500, and 1,000 mg/d) of extendedrelease divalproex sodium (DVPX ER) vs. placebo. The 7 selected trials reported headache frequency per month and $\geq 50 \%$ response rate as efficacy index.

\section{Quality assessment and publication bias}

The methodological quality of the trials was evaluated using the Risk of Bias tool in the Cochrane Collaboration. All of the included articles with either topiramate or DVPX ER reported random sequence generation. Information on allocation concealment, and the blinding of studies and participants was described. The trials had low risk of bias (Figure 2).

\section{Efficacy outcomes}

All the 7 selected trials measured monthly migraine days and the $\geq 50 \%$ response rate. The results showed that children receiving antiepileptic drugs significantly remitted the mean migraine days per month compared to placebo $(n=930$, 95\% CI: -0.48 to $-0.12, \mathrm{Z}=2.60, \mathrm{P}=0.009)$ (Figure 3). The heterogeneity was low $\left(\mathrm{I}^{2}=0 \% ; \mathrm{P}=0.47\right)$ so that fixedeffects model was used. However, no significant difference was found between the antiepileptics and placebo groups in the percentage of patients experiencing a $\geq 50 \%$ reduction in headache days per month $(\mathrm{n}=930,95 \%$ CI: 0.73 to 1.71, $\mathrm{Z}=0.51, \mathrm{P}=0.61$ ) (Figure 4). The data demonstrated significant heterogeneity $\left(\mathrm{I}^{2}=58 \% ; \mathrm{P}=0.03\right)$ and randomeffects model was considered.

\section{Subgroup analyses of efficacy outcomes}

Since the drug types significantly contributed to the outcomes, a subgroup analysis was conducted based 


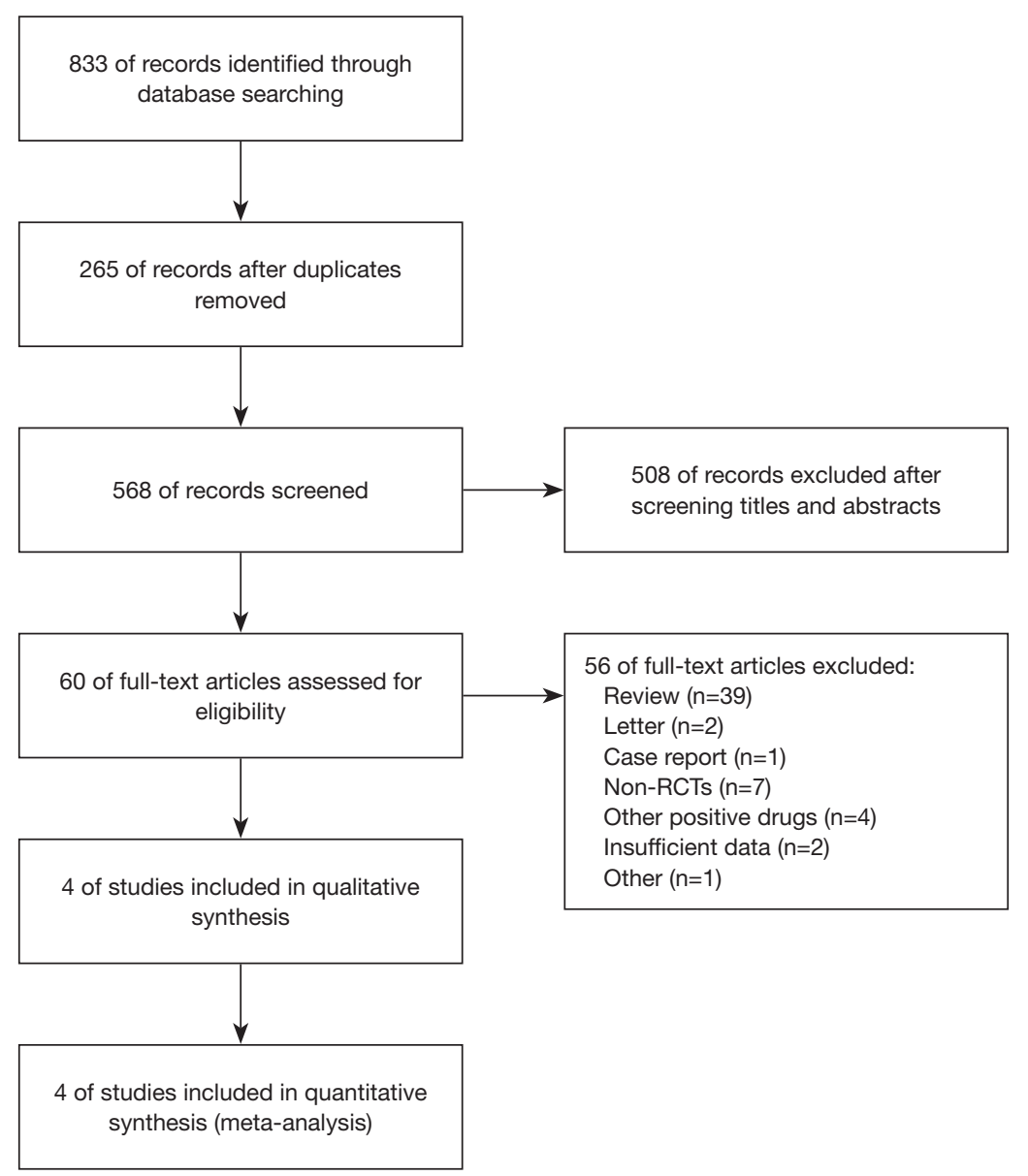

Figure 1 Study flow diagram.

on different types of antiepileptic drugs. The results demonstrated that topiramate could reduce monthly migraine frequency significantly compared with placebo $(M D=-0.70, n=489,95 \%$ CI: -1.16 to $-0.25, Z=3.01$, $\mathrm{P}=0.003)$. However, DVPX ER did not reduce monthly headache frequency compared with placebo $(n=441,95 \%$ CI: -0.70 to $0.47, \mathrm{Z}=0.38, \mathrm{P}=0.70$ ) (Figure 5). Neither topiramate ( $\mathrm{n}=489,95 \% \mathrm{CI}$ : 0.70 to $3.22, \mathrm{Z}=1.05, \mathrm{P}=0.30$ ) nor DVPX ER ( $\mathrm{n}=441,95 \% \mathrm{CI}$ : 0.59 to $1.25, \mathrm{Z}=0.82$, $\mathrm{P}=0.41$ ) improved the $\geq 50 \%$ reduction rate in monthly headache days compared with placebo (Figure 6).

\section{Adverse reactions}

The trials in this study all reported side effects and adverse reactions. The percentage of withdrawals was significantly higher in the topiramate ( $M D=2.28, n=489,95 \%$ CI: 1.09 to $4.78, \mathrm{Z}=2.18, \mathrm{P}=0.03)$ and DVPX ER $(\mathrm{MD}=1.87, \mathrm{n}=450$,
95\% CI: 1.02 to $3.43, \mathrm{Z}=2.03, \mathrm{P}=0.04)$ groups than the placebo group (Figure 7). The overall incidence of common side effects was higher in the topiramate group than the placebo group ( $\mathrm{MD}=1.55,95 \% \mathrm{CI}: 1.25$ to $1.91, \mathrm{Z}=4.04$, $P<0.0001)$ (Table 2). Although close to the significant level, no difference was found in the rate of side effects between the DVPX ER and placebo groups (MD $=1.27,95 \% \mathrm{CI}$ : 0.99 to $1.64, Z=1.88, P=0.06$ ) (Table 3). In the topiramate group, side effects such as weight loss, somnolence, paresthesia, dizziness, pharyngitis, sinusitis, abdominal pain, and other complications occurred more frequently than in the placebo group. Analysis of each common adverse reaction demonstrated weight loss ( $\mathrm{n}=353,95 \%$ CI: 1.24 to $17.51, Z=2.27, P=0.02)$, paresthesia ( $\mathrm{n}=489,95 \% \mathrm{CI}$ : 2.78 to $12.68, Z=4.61, P<0.01)$ and dizziness (95\% CI: 1.20 to $24.12, \mathrm{Z}=2.20, \mathrm{P}=0.03)$ significantly increased in the topiramate group (Table 2). Upper respiratory tract infection, nausea, nasopharyngitis, weight gain, somnolence, 


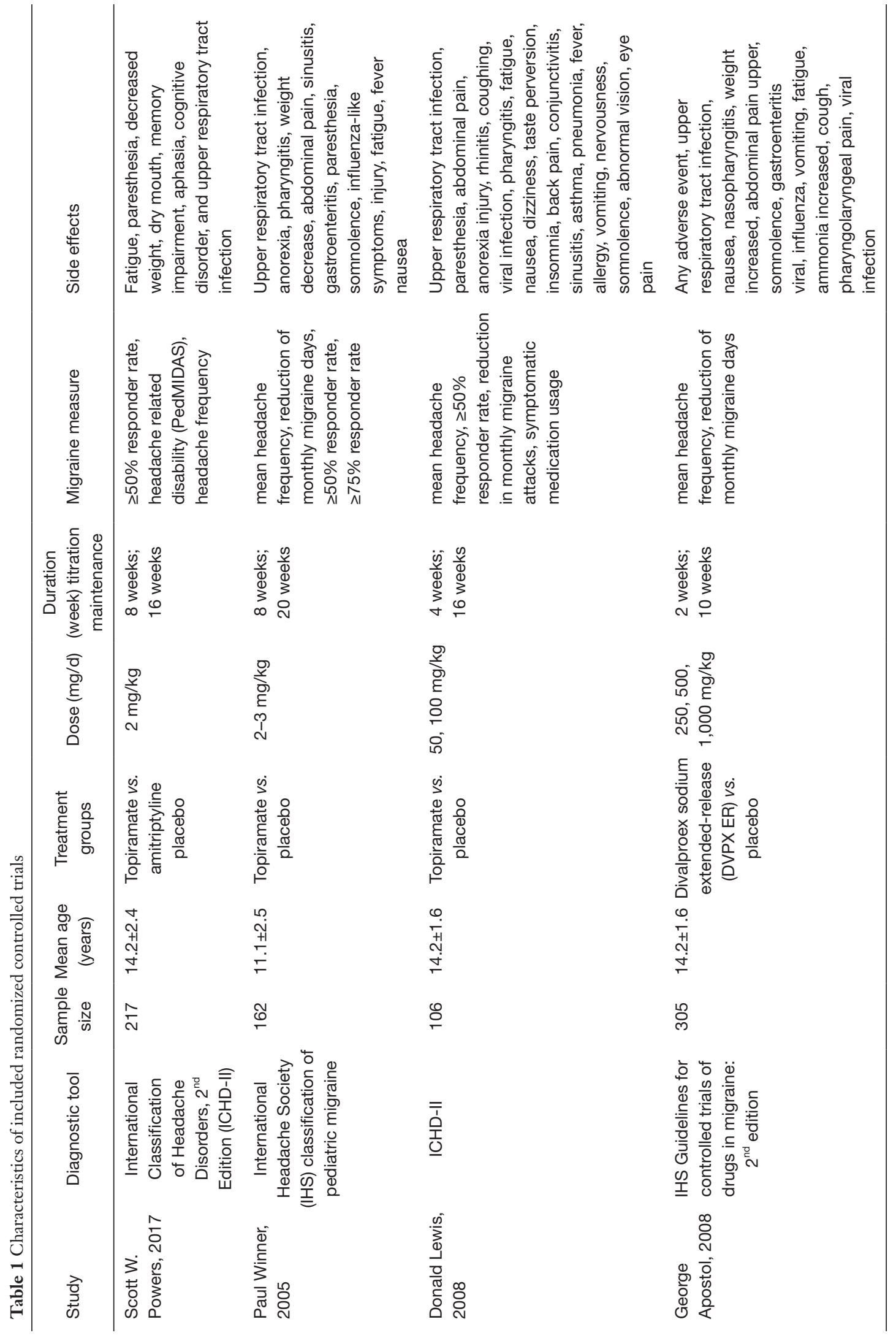



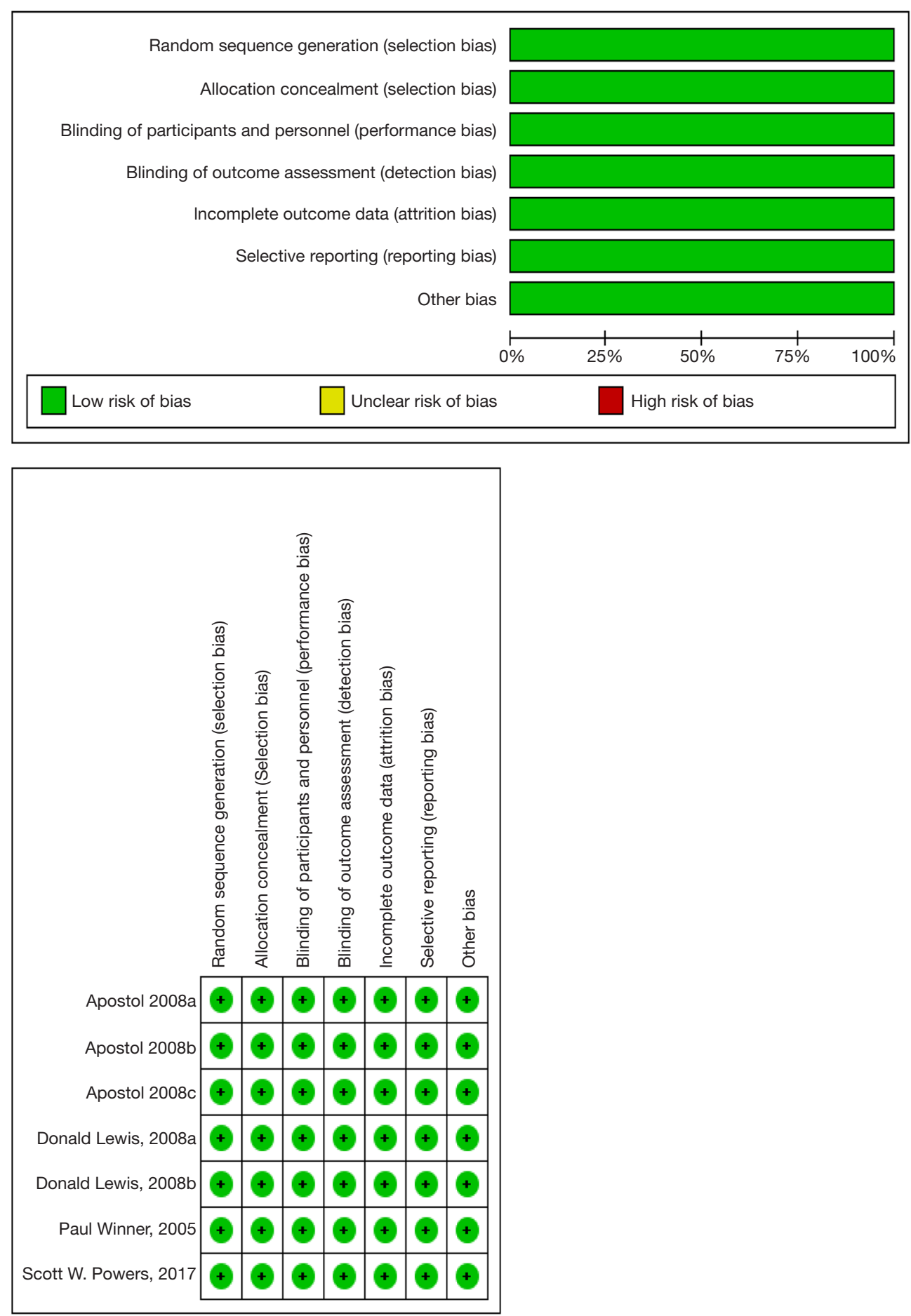

Figure 2 Risk of bias graph and summary.

viral gastroenteritis, influenza, and fatigue were the most commonly reported adverse events in the DVPX ER trial. However, the meta-analysis of each side effect demonstrated no significant difference in side effects between any dose of DVPX ER and placebo, although ammonia increased ( $\mathrm{n}=450,95 \%$ CI: 0.97 to $31.73, \mathrm{Z}=1.93, \mathrm{P}=0.05$ ) and weight 


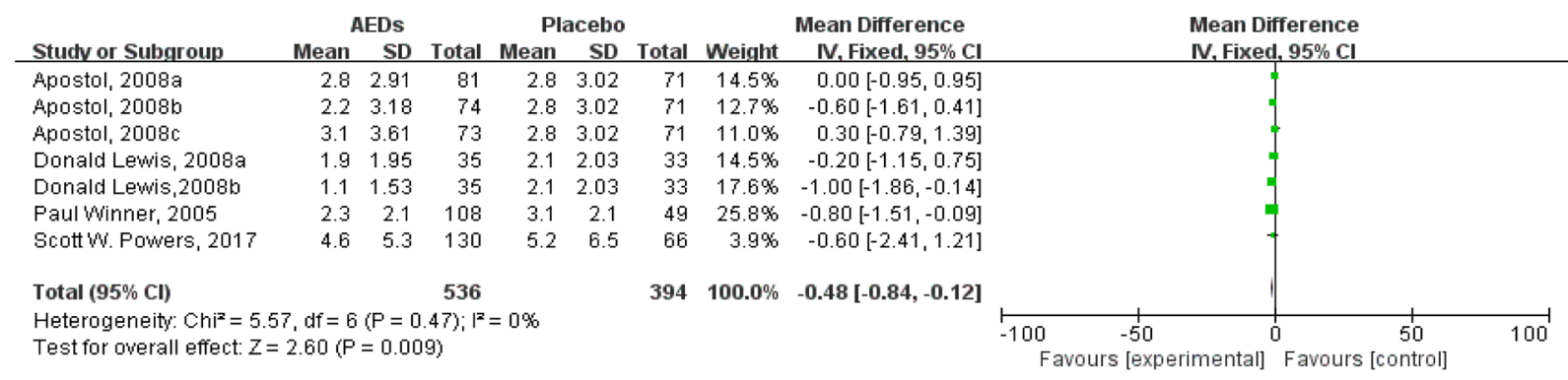

Figure 3 Comparison of the mean monthly migraine days between antiepileptics and placebo groups.

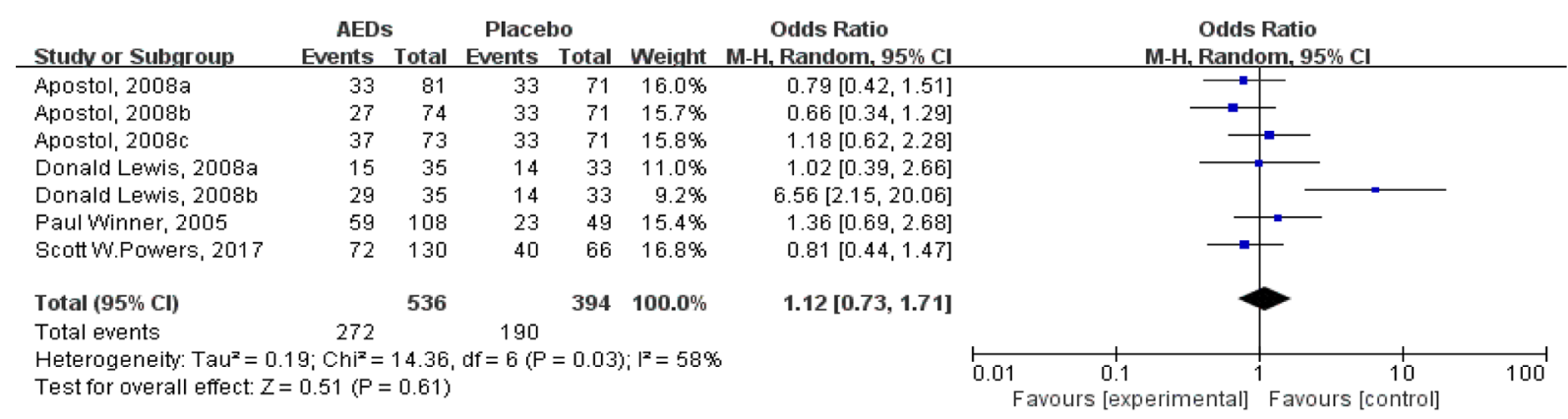

Figure 4 Comparison of $\geq 50 \%$ response rate between antiepileptics and placebo groups.

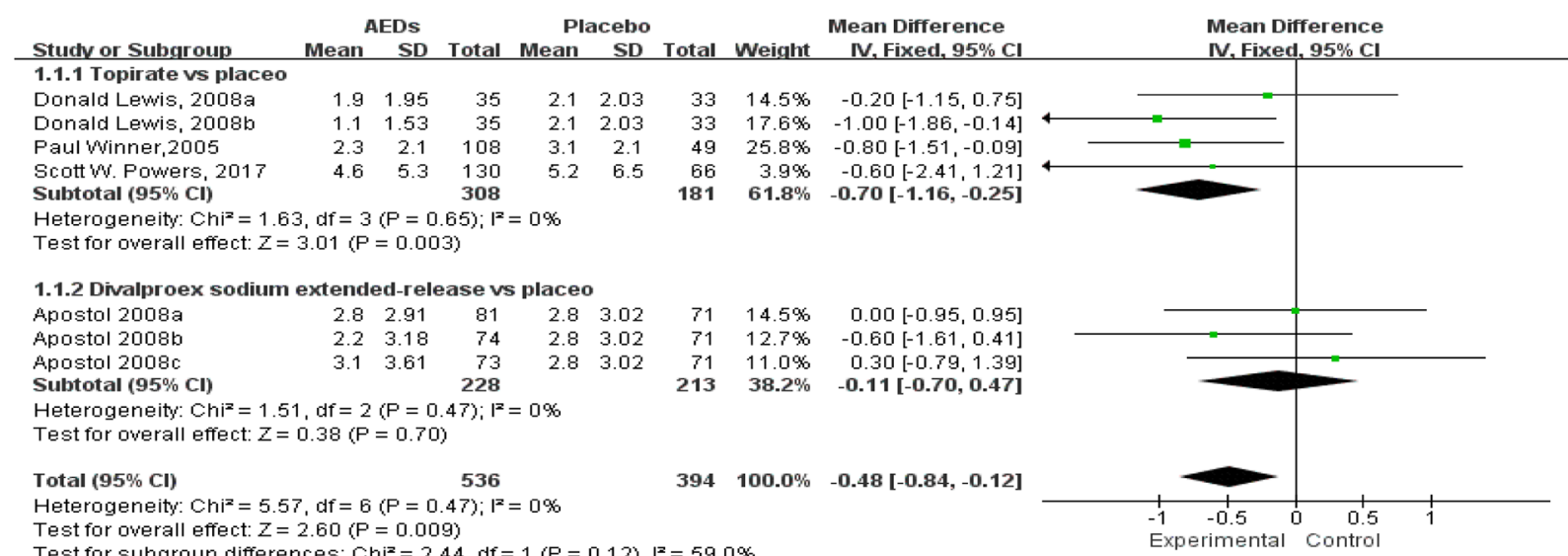

Figure 5 Subgroup analysis of monthly migraine days compared with placebo based on the type of antiepileptic drugs.

gain ( $\mathrm{n}=450,95 \% \mathrm{CI}$ : 0.98 to $13, \mathrm{Z}=1.94, \mathrm{P}=0.05)$ were close to the significant level (Table 3).

\section{Discussion}

This meta-analysis assessed the clinical efficacy and safety of antiepileptic drugs in pediatric migraine prevention compared with placebo. Reduction of headache days per month and $\geq 50 \%$ response rate were used as meaningful end points as IHS recommended.

Based on the successful evidence of adult trials, several drugs were used commonly in the prevention of pediatric migraine. However, after searching all of the databases, we found only a few RCTs evaluating the efficacy of 


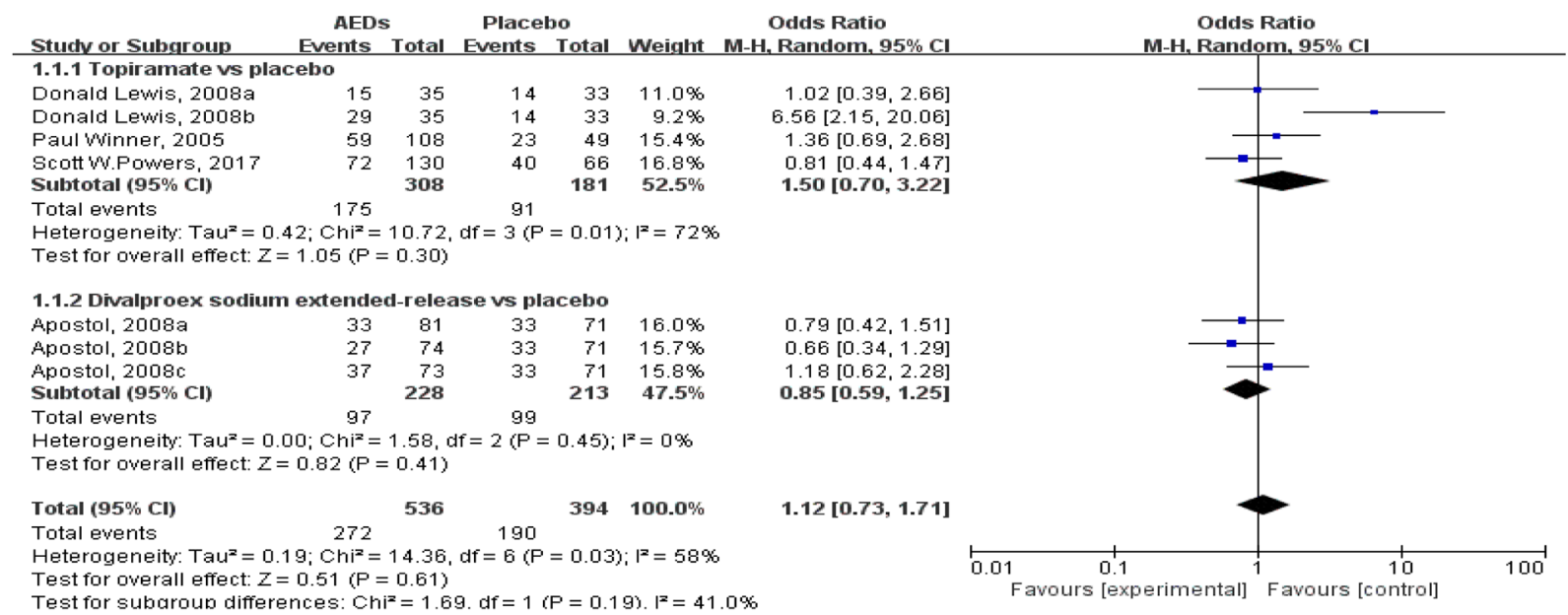

Figure 6 Subgroup analysis of $\geq 50 \%$ response rate compared with placebo based on the type of antiepileptic drugs.

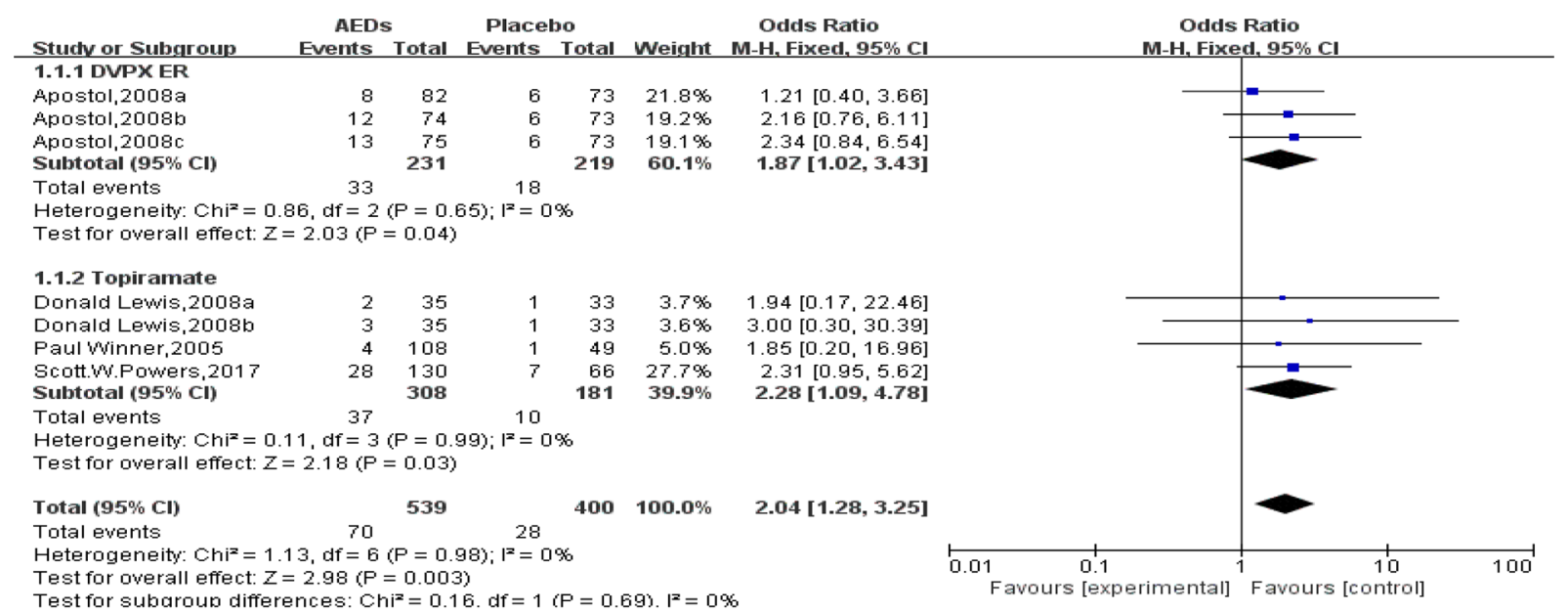

Figure 7 Comparison of withdrawals for any reason between antiepileptics and placebo groups.

antiepileptic drugs to prevent migraine in children and adolescents. Overall, 7 published RCTs with 794 participants comparing antiepileptics with placebo were identified.

As high-quality clinical trials were an essential part of the evidence base for treatment of migraine. In 2018, the IHS published guidelines for controlled trials of preventive treatment of chronic migraine in adults (24). Then in 2020, the guidelines for episodic migraine in adults were published (25). The first edition of the guidelines for preventive treatment of migraine in children and adolescents was issued in 2019 (26), which should be used in designing and conducting clinical trials of preventive treatments in pediatric migraine. Following the guidelines, we noticed one research by Lakshmi et al. (27) which was included in our study at first designed a baseline with medication use prior to randomization to med or placebo. The trial was excluded and all the 7 RCTs included in this study were consistent with the IHS guidelines.

The pooled analysis demonstrated that antiepileptic drugs could significantly reduce the mean migraine days per month compared with placebo. Nevertheless, no significant difference was found in the percentage of children with $\geq 50 \%$ response rate in headache frequency per month between antiepileptic drugs and placebo groups. The subgroup analysis of sample size reported the same pattern 
Table 2 Side effects and adverse reactions of topiramate $v s$. placebo

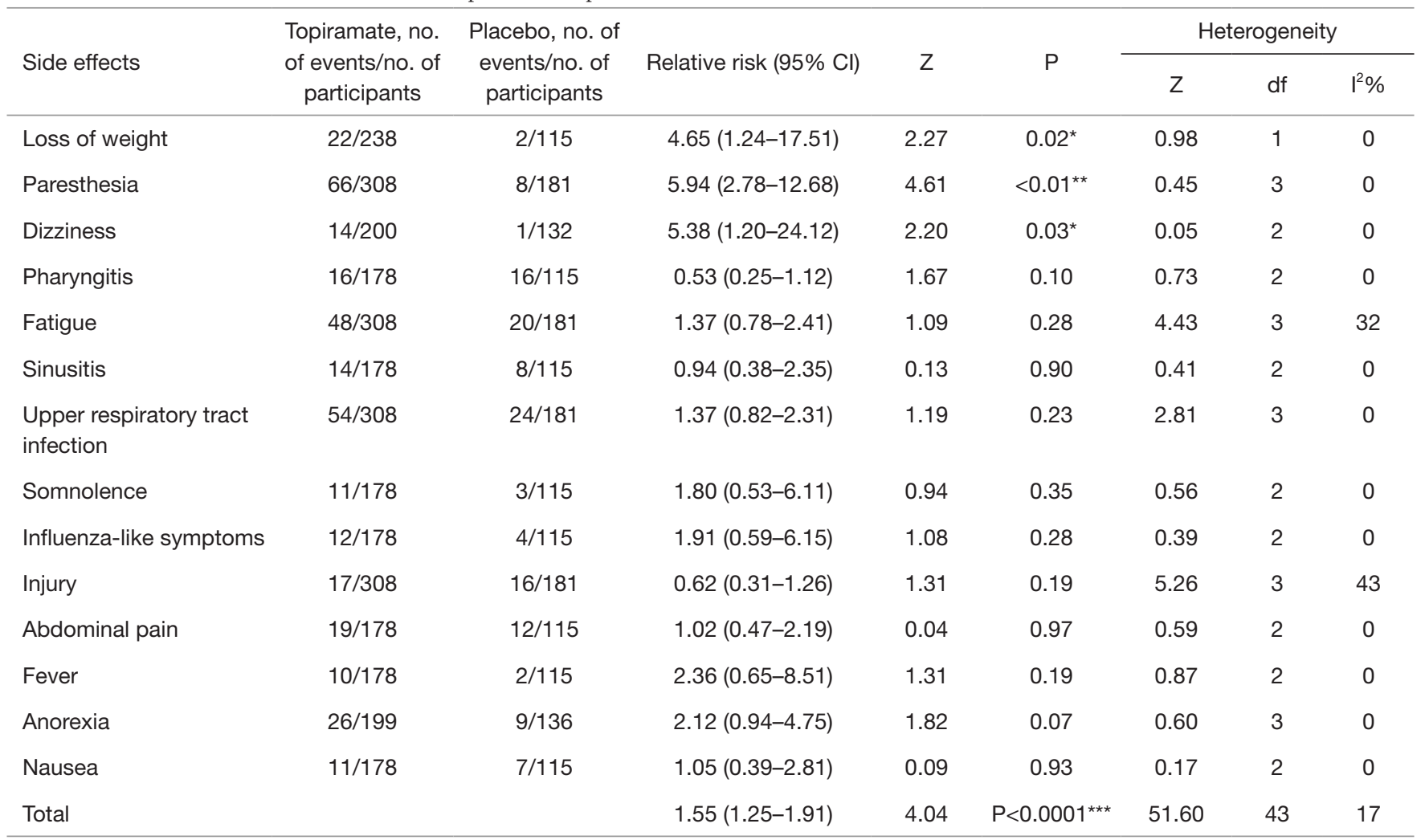

${ }^{\star} \mathrm{P}<0.05,{ }^{* \star} \mathrm{P}<0.01,{ }^{* \star *} \mathrm{P}<0.001$.

of results. The subgroup analysis based on drug types demonstrated that topiramate rather than DVPX ER could significantly remit the monthly migraine days compared to placebo. Both topiramate and DVPX ER failed to improve the $\geq 50 \%$ reduction rate in monthly headache days compared with placebo.

Migraine and epilepsy both are episodic neurological disorders with episodic manifestations. They might share the similar pathologic feature of neuronal hyperexcitability. Higher concentration of extracellular glutamate (the main excitatory neurotransmitter) leads in Cortical Spreading Depression and convulsions. So that AEDs are commonly used for migraine prophylaxis in both adult and children. In 2014, topiramate, a neuromodulator, became the first medication approved by the US Food and Drug Administration (FDA) to prevent migraine in adolescents 12-18 years old (28). Divalproex sodium has been proved to be effective in both prophylactic and acute treatment of migraine in adults. One daily dose of the extended-release (ER) formulation of DVPX sodium has also been approved by the US FDA for migraine prevention in patients
$>18$ years old.

Although our results showed that antiepileptics significantly reduced monthly migraine days, further research revealed that only topiramate could reduce migraine frequency per month, which was consistent with our previous work (29) and the practice guidelines published by American Academy of Neurology and the American Headache Society in 2019 (12). However, the practice guidelines included the trial of Lakshmi et al. which was without a true baseline. Although the efficacy of topiramate for preventing migraine in adults has been proved (30-32), evidence of topiramate for migraine prevention in children and adolescents was insufficient. Several randomized, double-blind trials reporting the clinical effect of topiramate for pediatric migraine prophylaxis yielded discordant results. A meta-analysis (33) demonstrated that topiramate could not reduce the headache frequency or improve the $\geq 50 \%$ response rate in 2017 . However, after carefully screening the study, we found there were some defects in the article such as inaccurate data, inclusion of Lakshmi's trial and not all of the topiramate dosages of were included. 
Table 3 Side effects and adverse reactions of Divalproex sodium extended-release (DVPX ER) vs. placebo

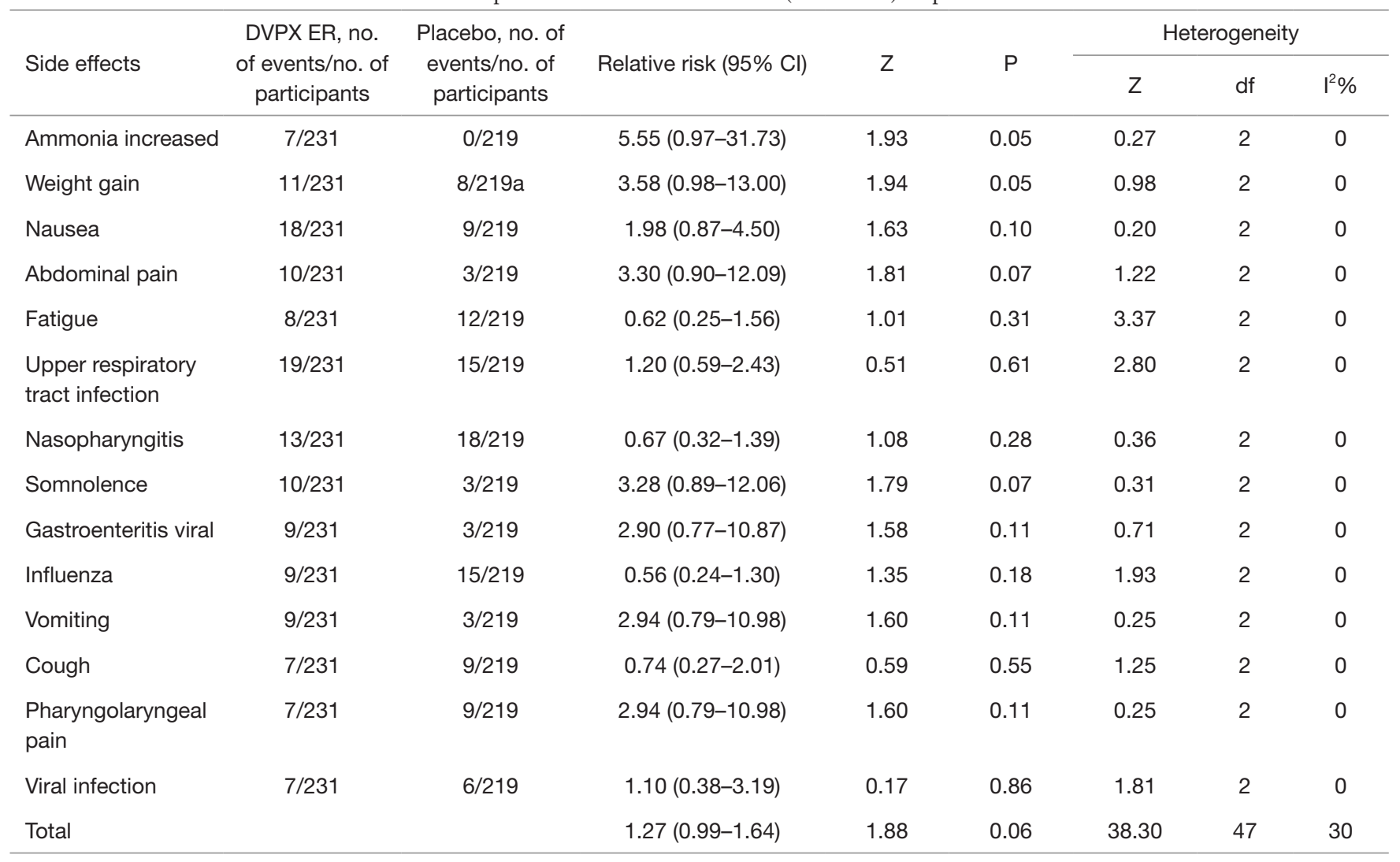

We revised the data and proved the efficiency of topiramate to prevent pediatric migraine.

Several RCTs revealed that DVPX significantly remitted the monthly headache frequency and improved the response rate in adults (16,34-36); however, evidence for DVPX in prophylaxis of pediatric migraine is very rare. Klapper et al. (34) has proved that DVPX ER $(1,000 \mathrm{mg} / \mathrm{d})$ was effective for migraine without aura in adults. In this study, significant difference was found in migraine frequency and response rate in neither of the dosages of DVPX ER (250, 500 and $1,000 \mathrm{mg} / \mathrm{d}$ ) compared with placebo.

DVPX ER and topiramate were well tolerated in most of the included studies; however, our study revealed that more patients withdrew from studies and experienced side effects in the DVPX and topiramate groups than in the placebo group. Studies (37-39) have reported many side effects of antiepileptics including DVPX and topiramate. Most adverse events were mild to moderate but some were serious or fatal. In 2008, the US FDA reported that all antiepileptic drugs were related to increased risks of suicidal ideation and behaviors. Furthermore, topiramate was believed to be associated with psychiatric side effects such as depression and anxiety (39). All the 4 studies with topiramate reported higher rates of side effects in the treatment group than the placebo group. Upper respiratory tract infection, weight loss, paresthesia, abdominal pain, fatigue, anorexia, somnolence, and cognitive disorders were the most common side effects in the topiramate group, which was in accordance with the previous studies in adults. Five out of 329 patients experienced serious adverse events related to topiramate ( 2 infections, 2 suicidal attempts, and 1 severe headache). Unlike topiramate, DVPX was related to the adverse events of weight gain and increased BMI (body mass index). Other reported most common side effects included upper respiratory tract infection, nausea, nasopharyngitis, elevated sex hormone-binding globulin (SHBG) levels and so on. Weight gain tended to increase over time but conversely, nausea relieved over time (40). The risk of suicidal behaviors of DVPX was relatively low compared with topiramate. No severe adverse events were reported in the DVPX group.

Of particular note is that neither topiramate nor DVPX ER 
achieved the greater proportion of children and adolescents experiencing a $\geq 50 \%$ reduction in mean migraine days than placebo. One study demonstrated a $\geq 75 \%$ response rate (not a $\geq 50 \%$ response rate) favoring $2-3 \mathrm{mg} / \mathrm{kg} / \mathrm{d}$ of topiramate compared to placebo (21). One RCT (22) showed that $100 \mathrm{mg} / \mathrm{d}$ of topiramate, not $50 \mathrm{mg} / \mathrm{d}$, led to a significantly improved $\geq 50 \%$ response rate. None of the DVPX ER doses demonstrated a significant advantage in improving the $\geq 50 \%$ response rate. Three possible reasons may explain the results. (I) For topiramate, the $\geq 50 \%$ response rate may be related to the dosages, as one study reported that when patients were treated with topiramate of $100 \mathrm{mg} /$ day, rather than $50 \mathrm{mg}$ /day, the $\geq 50 \%$ response rate significantly improved (22). (II) The FDA approved topiramate for children and adolescents 12-18 years old, but age of the children in our included studies ranged from 8-17 years. It can be challenging for young patients to describe the exact times of headache attacks. Atypical symptoms of pediatric migraine such as episodic dizziness, abdominal pain, and ophthalmodynia can be easily ignored by their guardians. (III) The placebo response rate of children was higher than adults. Compared with the placebo effects approximately $35 \%$ in adult patients with migraine, the placebo effects of children with headache could reach as high as $50 \%$ or more (41). In this study, the pooled placebo response rate was $48.43 \%$, with the $\geq 50 \%$ response rate of $52.42 \%$. The placebo response rates in topiramate and DVPX ER groups were $50.50 \%$ and $46.48 \%$, with the $\geq 50 \%$ response rate of $59.27 \%$ and $42.54 \%$ respectively. The differences between positive drugs and placebo were too small to illustrate the significance. The reasons for the higher placebo response rate (42) in children included that they could not take medicine on time at school; they more readily believed the efficacy of drugs when the symptoms were relieved, and "good doctor" effects.

Several RCTs appraised the efficacy of AEDs compared with other drugs. One RCT found cinnarizine significantly reduced headache frequency $v s$. topiramate (43). One included RCT (20) found there was no difference between topiramate and amitriptyline. Fallah et al. (44) reported that compared with propranolol, $50 \mathrm{mg} /$ day of topiramate significantly decreased the mean headache days per month among children and adolescents. One RCT (45) that measured the efficacy of sodium valproate $v s$. propranolol found that propranolol significantly decreased monthly migraine days $v s$. sodium valproate.

Several limitations of this study must be addressed. First, the evidence was limited because only 4 studies containing 7 clinical trials were eligible for this meta-analysis. Second, migraine often had a long course and symptoms tended to recur. So the duration of treatment may not have been long enough in the included studies. Third, we only measured monthly migraine days and $\geq 50 \%$ response rates in our study. More indexes such as headache intensity, acute medication use times, and other factors should be measured for a comprehensive evaluation. The outcomes of the $\geq 50 \%$ response rate showed obvious heterogeneity in this analysis $\left(\mathrm{I}^{2}=71 \%\right.$ and $59 \%$, respectively). The heterogeneity was significant in the topiramate group. However, only 4 trials were included and none of the variables could account for the variation.

\section{Conclusions}

In conclusions, topiramate $(2-3 \mathrm{mg} / \mathrm{kg} / \mathrm{d}$ and 50 , $100 \mathrm{mg} / \mathrm{d}$ ) could reduce monthly headache days in children and adolescents with migraine. However, it failed to improve the $\geq 50 \%$ response rate. DVPX ER $(250,500$ and $1,000 \mathrm{mg} / \mathrm{d}$ ) showed no difference from placebo in the prophylactic treatment pediatric migraine. Side effects seemed to be more frequent in topiramate and DVPX ER treated children but generally well-tolerated. Our study could provide evidence for the prevention of pediatric migraine for pediatricians and neurologists.

\section{Acknowledgments}

Funding: None.

\section{Footnote}

Reporting Checklist: The authors have completed the PRISMA reporting checklist. Available at https://dx.doi. org/10.21037/tp-20-478

Peer Review File: Available at https://dx.doi.org/10.21037/ tp-20-478

Conflicts of Interest: All authors have completed the ICMJE uniform disclosure form (available at https://dx.doi. org/10.21037/tp-20-478). The authors have no conflicts of interest to declare.

Ethical Statement: The authors are accountable for all aspects of the work in ensuring that questions related to the accuracy or integrity of any part of the work are appropriately investigated and resolved. 
Open Access Statement: This is an Open Access article distributed in accordance with the Creative Commons Attribution-NonCommercial-NoDerivs 4.0 International License (CC BY-NC-ND 4.0), which permits the noncommercial replication and distribution of the article with the strict proviso that no changes or edits are made and the original work is properly cited (including links to both the formal publication through the relevant DOI and the license). See: https://creativecommons.org/licenses/by-nc-nd/4.0/.

\section{References}

1. Camarda R, Monastero R, Santangelo G, et al. Migraine headaches in adolescents: a five-year follow-up study. Headache 2002;42:1000-5.

2. Hämäläinen ML. Migraine in children and adolescents: a guide to drug treatment. CNS Drugs 2006;20:813-20.

3. Bugdayci R, Ozge A, Sasmaz T, et al. Prevalence and factors affecting headache in Turkish schoolchildren. Pediatr Int 2005;47:316-22.

4. Laurell K, Larsson B, Eeg-Olofsson O. Prevalence of headache in Swedish schoolchildren, with a focus on tension-type headache. Cephalalgia 2004;24:380-8.

5. Karwautz A, Wöber C, Lang T, et al. Psychosocial factors in children and adolescents with migraine and tension-type headache: a controlled study and review of the literature. Cephalalgia 1999;19:32-43.

6. Powers SW, Patton SR, Hommel KA, et al. Quality of life in paediatric migraine: characterization of age-related effects using PedsQL 4.0. Cephalalgia 2004;24:120-7.

7. Hershey AD. Current approaches to the diagnosis and management of paediatric migraine. Lancet Neurol 2010;9:190-204.

8. Lewis DW, Scott D, Rendin V. Treatment of paediatric headache. Expert Opin Pharmacother 2002;3:1433-42.

9. Gelfand AA, Qubty W, Goadsby PJ. Pediatric Migraine Prevention-First, Do No Harm. JAMA Neurol 2017;74:893-4.

10. Rapoport AM. Acute and prophylactic treatments for migraine: present and future. Neurol Sci 2008;29 Suppl 1:S110-22.

11. Evers S, Afra J, Frese A, et al. EFNS guideline on the drug treatment of migraine--revised report of an EFNS task force. Eur J Neurol 2009;16:968-81.

12. Oskoui M, Pringsheim T, Billinghurst L, et al. Practice guideline update summary: Pharmacologic treatment for pediatric migraine prevention: Report of the Guideline Development, Dissemination, and Implementation
Subcommittee of the American Academy of Neurology and the American Headache Society. Neurology 2019;93:500-9.

13. Calabresi P, Galletti F, Rossi C, et al. Antiepileptic drugs in migraine: from clinical aspects to cellular mechanisms. Trends Pharmacol Sci 2007;28:188-95.

14. Zarcone D, Corbetta S. Shared mechanisms of epilepsy, migraine and affective disorders. Neurol Sci 2017;38:73-6.

15. Watkins AK, Gee ME, Brown JN. Efficacy and safety of levetiracetam for migraine prophylaxis: A systematic review. J Clin Pharm Ther 2018;43:467-75.

16. Linde M, Mulleners WM, Chronicle EP, et al. Valproate (valproic acid or sodium valproate or a combination of the two) for the prophylaxis of episodic migraine in adults. Cochrane Database Syst Rev 2013;CD010611.

17. Rompel H, Bauermeister PW. Aetiology of migraine and prevention with carbamazepine (Tegretol): results of a double-blind, cross-over study. S Afr Med J 1970;44:75-80.

18. Moher D, Liberati A, Tetzlaff J, et al. Preferred reporting items for systematic reviews and meta-analyses: the PRISMA statement. Int J Surg 2010;8:336-41.

19. Silberstein S, Tfelt-Hansen P, Dodick DW, et al. Guidelines for controlled trials of prophylactic treatment of chronic migraine in adults. Cephalalgia 2008;28:484-95.

20. Powers SW, Coffey CS, Chamberlin LA, et al. Trial of Amitriptyline, Topiramate, and Placebo for Pediatric Migraine. N Engl J Med 2017;376:115-24.

21. Winner P, Pearlman EM, Linder SL, et al. Topiramate for migraine prevention in children: a randomized, double-blind, placebo-controlled trial. Headache 2005;45:1304-12.

22. Lewis D, Winner P, Saper J, et al. Randomized, doubleblind, placebo-controlled study to evaluate the efficacy and safety of topiramate for migraine prevention in pediatric subjects 12 to 17 years of age. Pediatrics 2009;123:924-34.

23. Apostol G, Cady RK, Laforet GA, et al. Divalproex extended-release in adolescent migraine prophylaxis: results of a randomized, double-blind, placebo-controlled study. Headache 2008;48:1012-25.

24. Tassorelli C, Diener HC, Dodick DW, et al. Guidelines of the International Headache Society for controlled trials of preventive treatment of chronic migraine in adults. Cephalalgia 2018;38:815-32.

25. Diener HC, Tassorelli C, Dodick DW, et al. Guidelines of the International Headache Society for controlled trials of preventive treatment of migraine attacks in episodic migraine in adults. Cephalalgia 2020;40:1026-44.

26. Abu-Arafeh I, Hershey AD, Diener HC, et al. Guidelines 
of the International Headache Society for controlled trials of preventive treatment of migraine in children and adolescents, 1st edition. Cephalalgia 2019;39:803-16.

27. Lakshmi CV, Singhi P, Malhi P, et al. Topiramate in the prophylaxis of pediatric migraine: a double-blind placebocontrolled trial. J Child Neurol 2007;22:829-35.

28. FDA approves Topamax for migraine prevention in adolescents. J Pain Palliat Care Pharmacother 2014;28:191.

29. Wu X, Zhang Y, Lu M, et al. The Efficacy and Safety of Topiramate in the Prevention of Pediatric Migraine: An Update Meta-Analysis. Front Pediatr 2020;8:28.

30. Silberstein SD, Neto W, Schmitt J, et al. Topiramate in migraine prevention: results of a large controlled trial. Arch Neurol 2004;61:490-5.

31. Brandes JL, Saper JR, Diamond M, et al. Topiramate for migraine prevention: a randomized controlled trial. JAMA 2004;291:965-73.

32. Diener HC, Tfelt-Hansen P, Dahlöf C, et al. Topiramate in migraine prophylaxis--results from a placebo-controlled trial with propranolol as an active control. J Neurol 2004;251:943-50.

33. Le K, Yu D, Wang J, et al. Is topiramate effective for migraine prevention in patients less than 18 years of age? A meta-analysis of randomized controlled trials. J Headache Pain 2017;18:69.

34. Klapper J. Divalproex sodium in migraine prophylaxis: a dose-controlled study. Cephalalgia 1997;17:103-8.

35. Kaniecki RG. A comparison of divalproex with propranolol and placebo for the prophylaxis of migraine without aura. Arch Neurol 1997;54:1141-5.

Cite this article as: Jia G, Wang X, Lv H, Nonyane MSC, Hou H, Ma L, Shan P, Wu X. The efficacy and safety of antiepileptics in the prophylaxis of pediatric migraine: the meta-analysis of randomized controlled trials. Transl Pediatr 2021;10(7):1779-1791. doi: 10.21037/tp-20-478
36. Freitag FG, Collins SD, Carlson HA, et al. A randomized trial of divalproex sodium extended-release tablets in migraine prophylaxis. Neurology 2002;58:1652-9.

37. Redden L, Pritchett Y, Robieson W, et al. Suicidality and divalproex sodium: analysis of controlled studies in multiple indications. Ann Gen Psychiatry 2011;10:1.

38. Hesdorffer DC, Kanner AM. The FDA alert on suicidality and antiepileptic drugs: Fire or false alarm? Epilepsia 2009;50:978-86.

39. Mula M, Trimble MR, Lhatoo SD, et al. Topiramate and psychiatric adverse events in patients with epilepsy. Epilepsia 2003;44:659-63.

40. Tepper SJ. Antiepilepsy Drugs in Migraine Prevention: Editorial. Headache 2016;56:601-2.

41. Lewis DW, Winner P, Wasiewski W. The placebo responder rate in children and adolescents. Headache 2005;45:232-9.

42. Rothner AD, Wasiewski W, Winner P, et al. Zolmitriptan oral tablet in migraine treatment: high placebo responses in adolescents. Headache 2006;46:101-9.

43. Ashrafi MR, Najafi Z, Shafiei M, et al. Cinnarizine versus Topiramate in Prophylaxis of Migraines among Children and Adolescents: A Randomized, Double-Blind Clinical Trial. Iran J Child Neurol 2014;8:18-27.

44. Fallah R, Divanizadeh MS, Karimi M, et al. Topiramate and propranolol for prophylaxis of migraine. Indian J Pediatr 2013;80:920-4.

45. Bidabadi E, Mashouf M. A randomized trial of propranolol versus sodium valproate for the prophylaxis of migraine in pediatric patients. Paediatr Drugs 2010;12:269-75. 